\title{
Journals as a Global Threat to Pharmaceutical Research and Development
}

\author{
Asim Zeeshan ${ }^{1 *}$, Shahid Zeeshan', Sarwat Surriyya² \\ Electrical Engineering Department, College of Engineering Science, Institute of Business and Management, Karachi, PAKISTAN. \\ 2Anatomy Departments, Jinnah Sindh Medical University, Karachi, PAKISTAN.
}

\section{Sir,}

\section{Dear Editor}

In the scholarly arena, some publishers are capitalizing the model of open access publishing. This indicates that these publishers may anxious in accepting the manuscripts that are fallacious in term of academic or scientific quality is concerned and offering some publication charges to the author without specifying the essential editorial services. These publishers are in the scholarly arena known as predatory publishers and float an offensive term known as "predatory open access". ${ }^{1}$ However, the phenomenon of predatory journals has considered critical debate within the scholarly world for an extended period. More, recent threat that the scholarly world confront as a challenge within the academic sphere was 'Hijack journal.' The term refers to design clone webpage that replicates the mirror image of an Authentic Journal to fish the author's who accepts as true to send their work to a legitimate journal and also pay the publications charges.

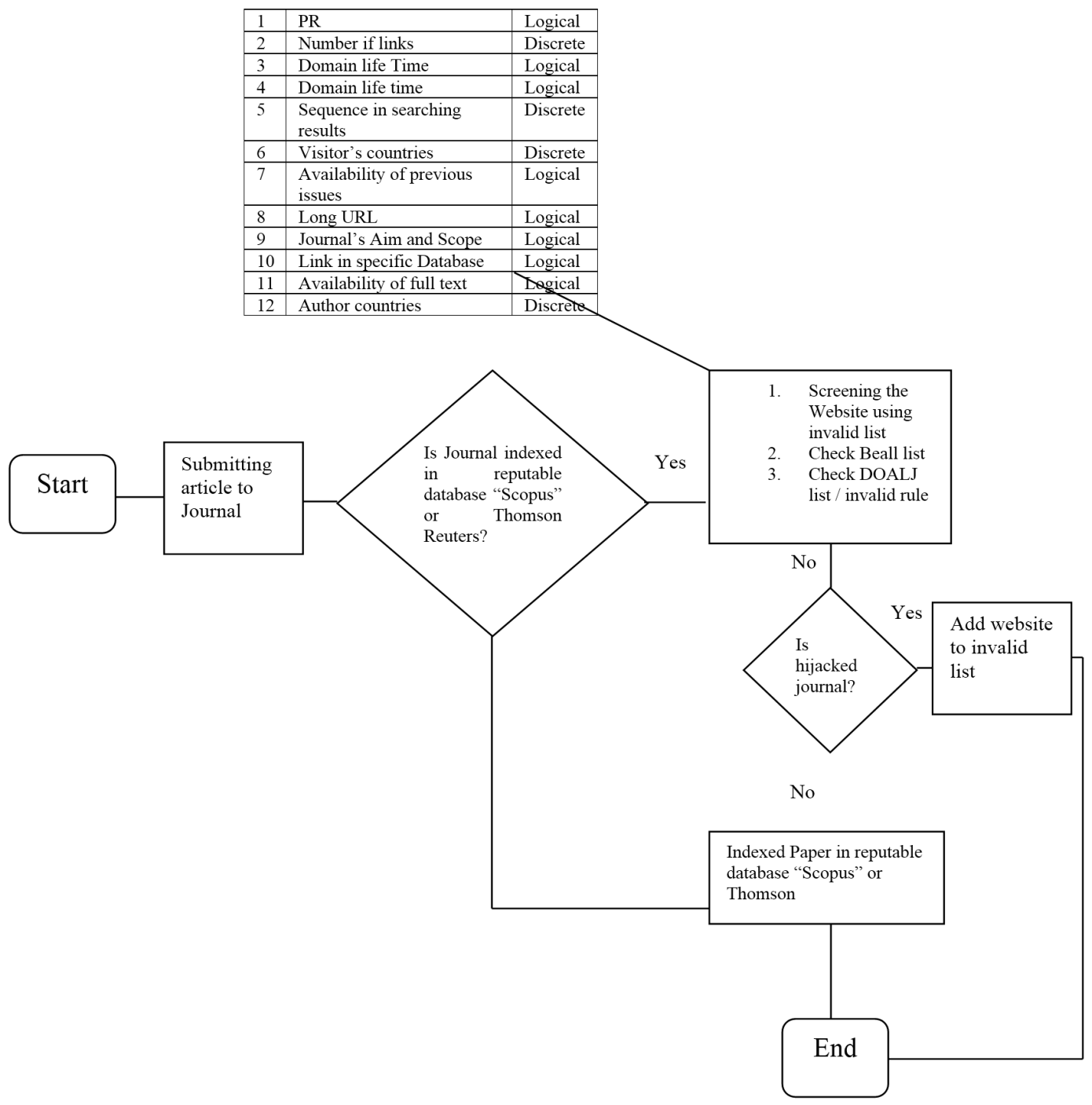

Figure 1: Flow chart on Preventive Algorithm before submitting manuscripts on any Journal. ${ }^{5}$ 
Inflating the reliability and validity of the findings of Pharmaceutical Research and Development (R\&D) along with tumbling publication partiality are absolute challenges for peer-viewed pharmaceutical journals. As they dedicated to recognizing as credible sources for the pharmaceutical R\&D, Pharmacological Sciences, Clinical Pharmacy, health and medicine policymaking. ${ }^{2}$ Besides, where to publish pharmaceutical research and how to circumvent fake journals are the additional challenges for Clinical Pharmacy. However, the world of Clinical Pharmacy in recent times has breached by new phenomena, i.e., 'Replica journals or Hijack journals'. Cyber criminals have been involved in building fake websites that mimic legitimate copy of scientific journals. ${ }^{3}$ They expended their racket to the clinical and pharmaceutical science journals recently by stolen several prominent pharmaceutical journals, including, British Journal of Pharmaceutical and Medical Research, Vitae-Revista (The Official Publication of the Faculty of Pharmaceutical Chemistry at the University of Antioquia, Colombia).

The main apprehension about this new trend is that the unreviewed process to inspect manuscripts that are published on fake website turn out to be the potential source for pharmaceutical practices and clinical pharmacy policymaking. Since such unquestionably research, articles will appear as a result of the systematic search and consider as part of systematic review on the pharmaceutical literature. A second critical threat regarding these counterfeit journals inflict on pharmaceutical science is that their unreliable findings will be a potential source for new hypotheses for pharmaceutical $R \& D$ that can be a vital threat to the reliability and validity for future pharmaceutical research findings. ${ }^{4}$ Warning the world of pharmaceutical industry regarding this new threat and taking into account meticulous scientific review of the citations to and from research article related to pharmaceutical science or clinical pharmacy this could be the most realistic measure on short-term bases. However, we must build a long-term method to protect the reliability and legitimacy of published pharmaceutical research. ${ }^{3}$

Before submitting, an article to Journal's author must understand some of the red flags as shown in Figure 1. As author, initiate the process by determining the journal indexing within the reputable database "Scopus or Thomson Reuters." If the journal is indexed within the database now, it is difficult for an author to recognize the authenticity of the journals. Therefore, to find the legitimacy for authenticated journals this article offers 12 intelligent decision making feature for evaluating the clone journals. Some of these features developed over a period of several observations for instance: Every legitimate journal webpage has a page rank (PR) in Google search engine several counterfeit journals do not have such a ranking. Also, compare the webpage source codes between the authentic journal and counterfeit journal. The external link also considers as a significant feature to distinguish in between authenticated journal and hijacked journals. The essential values of some elements can disengaged from intermediary data service also can utilize to identifying the difference in between fake and original journal, for instance, WHOIS databases (http://whois.domaintools.com) to allocate the value to web 'Domain Lifetime' while Alexa database (http://www.alexa.com) for 'Visitors' countries'. The value of 'Authors' country' has been identified by using data mining or text mining on the journal's webpage and research article published. If the author identified that journal had hijacked than add the journals into invalid list otherwise indexed the papers within a reputable database. ${ }^{5}$

In conclusion, this research article considers the significant characteristics of clone or hijacked Pharmaceutical journal along with critical information that most of these cybercriminal utilizes to exploit the authors to publish their manuscripts to some of these counterfeit journals due to quick editorial process. This article highlights how cyber criminals posed an important threat to reliability and validity for the discovery of future pharmaceutical research. It is the author responsibility to refuse these questionable journals; otherwise, the population of these fraudulent journals will continuously grow to obstruct and damage the reputation of valuable Pharmaceutical research.

\section{CONFLICT OF INTEREST}

The authors declare no conflict of interest.

\section{REFERENCES}

1. Tin L, Ivana B, Biljana B, Ljubica IB, Dragan $M$, Dušan $S$, et al. Predatory and Fake Scientific Journals/Publishers - A Global Outbreak with Rising Trend: A Review. Geogra Pannon. 2014;18(3):69-81.

2. Dadkhah M, Maliszewski T, Jazi MD. Characteristics of Hijacked Journals and Predatory Publishers: Our Observations in the Academic World. Trends Pharm Sci. 2016;37(6):415-8

3. Jalalian, Mahboobi. Hijacked journals and predatory publishers: Is there a need to re-think how to assess the quality of academic research. Walailak J Sci. 2014;11(5):389-94

4. Bohannon. How to hijack a journal. Science. 2015;5(4):903-5

5. Dadkhah M, Maliszewski T, Lyashenko VV. An approach for preventing the indexing of hijacked journal articles in scientific databases. Behav Inform Technol. 2016; 35(4):298-303

Correspondence

Dr. Asim Zeeshan,

Assistant Professor, Department of Electrical Engineering, College of Engineering Science, Institute of Business and Management (loBM), Karachi, PAKISTAN.

Phone: +601111794855

Email: zeeshanasimump@gmail.com DOI: 10.5530/jyp.2020.12.38

Article History: Submission Date : 31-12-2018; Revised Date : 04-02-2019; Acceptance Date : 26-02-2019.

Cite this article: Asim Z, Shahid Z, Sarwat S. Journals as a Global Threat to Pharmaceutical Research and Development. J Young Pharm. 2020;12(2):185-6. 